\title{
Enhancing Writing Ability and Self-regulation through Teacher-led Collaborative Modeling
}

\author{
Reza Tahmasebi \\ English Department, Torbat-e Heydarieh Branch, Islamic Azad University, Torbat-e Heydarieh, Iran \\ Hossein Khodabakhshzadeh (Corresponding author) \\ English Department, Torbat-e Heydarieh Branch, Islamic Azad University, Torbat-e Heydarieh, Iran \\ E-mail: mathesistbt@gmail.com
}

Received: 09-10-2016

Published: 01-03-2017
Accepted: 06-12-2016

doi:10.7575/aiac.ijalel.v.6n.2p.239
Advance Access Published: January 2017

URL: http://dx.doi.org/10.7575/aiac.ijalel.v.6n.2p.239

\begin{abstract}
Teacher-led collaborative modeling can provide a condition through which the teachers and learners cooperate, negotiate, discuss, and provide different degrees of support to compose and edit written texts. The presupposition in this study was that this type of modeling can improve the writing ability of the EFL learners as well as their self-regulation in writing. To test the main hypotheses of the study, eighty five female upper-intermediate EFL students studying English as a foreign language at the Ayandehsazan Language Institute (A.L.C) in Torbat-e- Heydarieh , Iran, ranging in age from 14 to 20 sat for the Quick Placement Test (QPT) and 50 students were selected based on their scores on the QPT test. They were divided into two groups. The learners in the experimental group received instruction according to the stages of instruction using collaborative modeling. The participants in the control group, on the other hand, didn't receive any collaborative modeling instruction. The participants in both groups sat for the writing test as well as a selfregulation test for writing. The results revealed that the experimental group outperformed the control group concerning their writing performance. However, there was no significant difference between the self-regulation ability of the participants in these two groups. The findings of the study have implications for pedagogy as well as research.
\end{abstract}

Keywords: Teacher-led collaborative modeling, self-regulation, writing performance

\section{Introduction}

The importance and popularity of Second Language Writing (SLW) as a productive skill in EFL contexts, especially in light of $21^{\text {st }}$ Century demands (Johannesen, 2001) have attracted the attention of a plethora scholar. Although the importance of writing has been recognized in the curriculum, teachers have not been trained to teach writing strategies (Almeida, 2012; Almaida\&Simao, 2007) and students have difficulty planning and revising their writing. However, as a number of scholars such as Leki, Cumming, and Silvia (2008) and Hinkel (2011) have pointed out, there is as yet surprisingly little research evidence on what constitutes best practice in L2 writing instruction, and to date,no specific approach or method has been validated through research.

There is no doubt that cognition is a cornerstone of writing and its development. However, the cognitive versions utilized by cognitivist approaches are usually "discrete" ones, which consider cognition as an intrinsic affair bounded by brain (Atkinson, 2011b). On the other hand, as a solitary activity (Yarrow \& Topping, 2001) writing lacks the interaction needed to make it as interactive and dialogue-based as Vygotsky (1978) mention. In comparison with spoken language through which different external feedbacks help partners stimulate and monitor thoughts, the written form of the language has to be maintained by internal process (BereiterScardamalia, 1987).

In case the writer is also a Foreign Language Learner (FLL), the corrective feedbacks given by a teacher, instructor, or peer may foster an extra cognitive processing which is particularly focused on form. This processing may provoke a reconstruction of explicit mental-linguistic representations (Bitchener, 2012; Polio, 2012) or leads to an expansion of metacognitive revising strategies (Ferris, 2010).

Teacher-led collaborative modeling is a type of scaffolded instruction in which the teacher and learner compose and edit an academic text in a process that involves negotiation and shared responsibility (Rosemary, 2014). Collaborative writing can lead to different types of cognitive benefits (Topping Ehly, 1998) such as increased engagement and time spent on task, immediacy and individualization of help, goal specification, explaining, prevention of information processing overload, prompting, modelling and reinforcement, among which the last two ones are more related to this study.

One of the important factors when teaching writing is the knowledge of learners' beliefs and behaviours such as selfefficacy and self-regulation (Hamman, 2005). Teacher-led collaborative writing is a way to enhance the effective 
writing strategies that lead to a self-regulatory process and enable learners to better understand how writing selfregulatory processes develop (Zimmerman \& Risemberg, 1997).

Up to the present time, the teacher-led collaborative modeling seems to have been supposed to improve not only the students' writing ability but their self-regulation in this area. However, this approach needs to be revisited empirically before it can be introduced into the EFL writing classroom. To accomplish the purpose, this study was designed to perform an empirical reassessment of the previous claims along with a tendency to answer the key question that concerns whether or not a teacher-led collaborative model will improve EFL students' writing performance and selfregulation in this area. There is an irrefutable need for both teachers and learners to make a better sense of the social interaction and cognitive processes underlying writing as an academic skill. Scholars have emphasized the significant role of the text modelling (Macbeth, 2010). Teacher-led collaborative modelling, in fact, invokes a genuine cooperation and negotiation between teachers and learners (Wette, 2015) while it pushed the learners towards a kind of independence as their competence develops.

The social interaction between the teacher and students can increase the learners' awareness about the task demands of the written texts. It can also provide teachers with valuable feedback about learners' progress as well as their developmental needs and enables teachers to provide enough support in learners' attempts and performances in writing tasks.

\section{Related Literature Review}

\subsection{Theoretical background and concepts}

Ken Hyland (2013) once posited that English appears to becom less of a language than a set of basic academic skills for many users, a statement which seems to be far from an overstatement today.Under these conditions, teachers are increasingly required to gain deeper insight into how L2 writing instruction can help learner writers to get ready for the requirements of the academic study. Recently, genre-based approaches to teaching writing have gained considerable attention due to growing awareness of the significance of both social interaction and cognitive process in the development of skills. However, there are a number of criteria associated with collaborative modeling for L2 writing ability. These criteria, including collaborative writing and teaching, teacher-student interaction based on scaffolding, description of scaffolding, modeling as instructional scaffolding, beliefs about writing and the role of teachers along with self-regulation are crucial to the objectives of this study.

\subsection{Collaborative writing}

Among several mediating factors related to the cognitive advantages of peer-assisted learning (Topping \& Ehly,1998; Topping, 2001 a), those with immediate relevance for collaborative writing include: improved engagement and time dedicated to a task, immediacy and individual nature of assistance, goal setting, explaining, averting information processing overload, motivating, modeling and reinforcement. A number of these factors can be equally assigned to both partners in the peer tutoring setting, whereas others are more tailored to one or other role. However, there is paucity of evidences substantiating that peer interaction during writing can actually improve children's writing at school. This is mainly due to the fact that the descriptive nature of most studies on collaborative writing by schoolchildren outweighs their evaluative nature (Louth, McAllister, \& McAllister, 1993).

The studies of a many scholars on the development of L1 writing skills (e.g., Daiute, 1986; Wells, Chang, \& Maher, 1990) suggest that students should adopt a collaborative approach during the writing process. It means that learners assume a shared responsibility with respect to the text composition. By stimulating a sense of co-ownership, this encourages students to participate in the decision makings relevant to all aspects of writing including structure, content and language. This collaborative approach to writing is what Ede and Lunsford (1990) refer to as singular text/plural authors approach.

In a collection of studies on exploring the adoption of collaborative writing in English as a second language (ESL) classrooms, Storch and Wigglesworth found that peers tended to nurture scaffolding, particularly when collaborative situation was ripe for the transfer of knowledge amongst group members (Storch, 2002a, 2002b, 2005; Storch\& Wigglesworth, 2007; Wigglesworth \&Storch, 2009, 2012).

To gain deeper insight into the nature of collective scaffolding, there has been an extensive body of research on learners' interaction in the process of undertaking collaborative writing activities in both face-to-face and online environments. In these studies, the emphasis has been mainly on the frequency of language-related episodes (LREs), which are defined as "any portion of a dialogue in which students discuss the language they produce, question their language use, or correct themselves or others" (Swain \&Lapkin, 1998, p. 328). There are few studies on collaborative writing in which the strategies of talking about other components of written texts, such as content or structure, by learners have been addressed (Elola\&Oskoz, 2010; Storch, 2005).

\subsection{Modeling as instructional scaffolding}

Modeling, as a form of scaffolding, encompasses a teacher-led analysis and assessment of text models, description of writing process, collaborative creation of texts by learners and the teacher, and preparing tasks that should be completed by learners in pairs or groups. Cumming (1995) presents a typology that incorporates three types of modeling:

1-Text modeling (analysis of faulty or proficient completed texts); 
2- Cognitive modeling (presentation of masterful composing process, as a strategy commonly used in the process approach to writing instruction);

3- Social modeling (a negotiated construction of text by learners and the teacher or peers).

The analysis of the instructional strategies used by four L2 writing teachers (Riazi, Lessard- Clouston, and Cumming 1996) has shown the regular application of text modeling and social modeling in particular. The usefulness of text models (Macbeth 2010) and of writing or revision tasks accomplished collaboratively in pairs or groups has been documented in studies on academic L2 writing (Bhagat and O'Neil 2011); however, there is a paucity of reference to instruction that includes teacher-led collaborative modeling.

Wette (2014) examined all three types of modeling in the teaching of seven L2 writing teachers findings that confirmatory evidence of Cumming's statement in that modeling constituted a regular portion of the instructional collection of participants. In this study, two types of social modeling were differentiated. The first one was collaborative modeling in which teachers worked cooperatively with the whole class group. In this model, the teachers elicited contents, reorganized contributions of students, posed questions, and gave feedback with the purpose of writing or editing a text (e.g. a review of literature, summery? or a section of an essay). The second one is peer modeling in which students work in pairs or groups independently of the teacher to compose or edit a text.

In the teacher-led collaborative modeling, the preliminary stage of genre-based instruction where the teacher offers clear instructions and assumes the key responsibility for the analysis and construction of text is linked to the final stage of independent text composition. It is achieved through second stage of activity which is characterized by responsibility contributes to the current knowledge of suitable instructional strategies used in L2 writing teaching. Sharing. In this paper, an analysis of various episodes of collaborative modeling applied to the broader study of all three types of modeling is presented.

\subsection{Writing and self-regulation}

Self-regulation offers a combination of learning behaviors or strategies, motivation, and metacognition (e.g. Pintrich, 2000 ; Schunk\&Ertmer, 2000; Winne,1995).In writing tasks, the perceptions of students about their self-efficacy are a strong predictor of their academic success (Zimmerman \& Bandura, 1994), which can significantly affect their attempts and inherent motivation (Perry, 1998). Additionally, writing cognitively demanding tasks is associated with higher levels of intrinsic motivation and self-monitoring activities (Miller et al., 1993; Perry, 1998).

The way students plan their writing, such as content production, reference to the library sources, and even selection of planning in the first place is dependent on their knowledge of writing strategies (e.g., Bereiter\&Scardamalia, 1987; Gordon, 1990; Perry, 1998).For instance, studies show that second- and third graders have a tendency to look for more efficient strategies on their own prior to seeking assistance from others (Perry, 1998).Moreover, even students believed to have low-ability had a positive attitude towards their writing improvement and demonstrate a mastery focus. Therefore, it is not surprising that there is a recurrent suggestion of self-regulatory strategies for academic writing (e.g., Harris\& Graham, 1996; Anger, 2001; Zimmerman \&Risemberg, 1997).

It may be because students receiving effective writing strategies can attribute their writing problems to improper strategy use rather than a lack of writing "talent". Moreover, it may be due to the fact that students who believe to be "poor writers," or perceive writing ability as a "talent" may not put in sufficient efforts to learn and implement writing strategies, even when proper instruction and support is offered by a teacher. A chief objective is to have a clear perception of writing self-regulatory processes (Zimmerman \&Risemberg, 1997). Also, another equally important concern is the reasons students refrain from using self-regulation in writing activities (Graham \& Harris, 1997; Zimmerman \&Risemberg, 1997), even after extensive instruction.

\section{Method}

This study, in fact, aims to get insight into the instructional role of modeling about which little is known to date (Dörnyei 2007). Scaffolding as one of the key factors in learning(Stone, 1998) plays its own role which is mostly a support for the completion of a task that learners otherwise might not be able to complete (Van de Pol, Volman, \&Beishuizen, 2010). These trends are generally a Vygotskian-inspired analysis of scaffolding. According to Vygotsky learning primarily takes place in a social rather than an individual level. A teacher-student interaction, in fact, paves the way towards a setting in which participants are active rather than passive ones.

\subsection{Participants}

Eighty five female upper-intermediate EFL students studying English as a foreign language in the Ayandehsazan Language Institute (A.L.C) in Torbat-e- Heydarieh, Iran, ranging in age between 14 to 20 were selected based on their scores on the Quick Placement Test (QPT). They had studied English for 12 semesters in A.L.C. The sample (N=50) was selected based on the participants' scores on the Quick Placement Test (QPT) and were randomly assigned into two groups of 25 i.e., experimental and control group. The learners' mother tongue was Persian.

\subsection{Instrumentation}

\subsubsection{Quick Placement Test (QPT)}

To ensure the homogeneity of the participants, QPT developed by Oxford University Press and University of Cambridge Local Examinations Syndicate (2001) (grammar, vocabulary, cloze test) was administered to 85 EFL students. The test includes 60 multiple-choice items and those whose scores were between 40 to 47 out of 60 were 
known as upper-intermediate ones and were randomly assigned to control $(\mathrm{N}=25)$ and experimental $(\mathrm{N}=25)$ groups. The QPT has already been validated in 20 countries through administering to more than 2,000 Learners. The reliability indexes of the test calculated by the trial phases are close to 0.9 for the 60 item test.

\subsubsection{General Writing Test}

General topics were given to the participants in both groups to be developed into paragraphs. This was done on the premise that the participants' writing ability would be assessed following an analytic scoring procedure. The procedure of scoring was similar to one of the best known analytic rubrics in ESL developed by Jacobs and her colleagues (Jacobs, ZingrafWormuth, Hartfiel\&Hughey, 1981) according to their rubrics, essays are rated on five different rating dimensions of writing quality,each having a different weight: content (30 points), organization ( 20 points), vocabulary (20 points), language use ( 25 points), and mechanics (5 points).

\subsubsection{Self- regulation Questionnaire}

The test of self-regulation in the form of a questionnaire was taken from Talebinezad and Negari (2007). It was adapted from Printrich, Smith, Garcia, and McKeachie, (1991) which was a manual for the use of the Motivated Strategies for Learning Questionnaire (MSLQ). 31 items of this questionnaire whose scales were adapted to measure specifically the students 'self-regulation in writing tasks were mostly based on five scales in the learning strategies section (metacognitive self-regulation, time and study environment, effort regulation, peer learning and help seeking. Cronbach's alpha for the scale was .76

\section{Procedure}

In order to detect the effect of teacher-led collaborative modeling on Iranian EFL upper intermediate learners,_ the following procedure was conducted. The participants' placement in the experimental and control group was determined by means of QPT. There were 25 upper intermediate EFL learners in each group. They all sat for a writing test as a pre and posttest as well as a writing self-regulation questionnaire. The study lasted for 20 sessions with two 90-minute sessions per week.The first phase of the study was completed within a 90-minute session period. During the session, the instructor in the experimental group worked on the organization of the paragraph writing as well as the mechanics of writing such as comma, capitalization, word choice, etc. The teacher and the students went through a discussion about the general organization while the learners tried to apply it on the tasks at hand first individually then in pairs. In the next stage, the teacher displayed a text with jumbled organization on the screen to elicit the learners' suggestions. Some of the students referred to the earlier tasks they had and others asked for the teacher's help. In the next step the learners were involved in writing tasks to attempt the organization as well as the mechanics of writing through which an independent completion of the tasks was expected.After the first five-session period, the teacher started a fifteen-session period consisting of three five-session working on the three different types of paragraphs i.e., process, cause and effect and summary text. According to the stages of instruction in collaborative modeling the instructor generally followed the following steps:First, the teacher tried to integrate the teacher talk and discussion as a teacher-led type of instruction. This was done in the teacher modeling stage specifically done for different types of paragraphs (see the lesson plans in appendix). Generally at this stage the learners enjoyed the teacher's support and feedback while negotiating with peers in groups to complete the task. Second, in the modeling stage the learners and the teacher worked cooperatively to construct a text and edit it afterward. The learners had a chance to consult their earlier drafts individually or in groups. In the last stage, the teacher tried to consolidate and extend learning by assigning a new task and asking the learners to complete it mostly independently.

\section{Results}

An assessment of the normality of data is a prerequisite for many statistical tests because normal data are an underlying assumption in parametric testing. First of all, in order to ensure the normality of data, Kolmogorov-Smirnov (KS) Test and Shapiro-Wilk was used for all the data. It can be seen in Table 1 that the data were normally distributed since the "a" value of the KS Test and Shapiro-Wilk is greater than .05, the distribution of the data is normal, so parametric tests can be applied for further analysis.

Table 1 . Test of Normality of the Data

\begin{tabular}{rrrrrrr}
\hline & \multicolumn{3}{c}{ Kolmogorov-Smirnov a } & \multicolumn{2}{r}{ Shapiro-Wilk } \\
\hline & Statistic & Df & Sig. & Statistic & Df & Sig. \\
Writing Pretest & .155 & 50 & .094 & .904 & 50 & .081 \\
Writing Posttest & .200 & 50 & .063 & .922 & 50 & 073
\end{tabular}

a. Lilliefors Significance Correction

Table 2 indicates the descriptive statistics for OQPT. As can be seen, the mean score and standard deviation of the experimental group $(\mathrm{M}=43.84, \mathrm{SD}=2.54)$ and control group $(\mathrm{M}=44, \mathrm{SD}=2.04)$ are approximately the same. 
Table 2. Descriptive Statistics for Oxford Quick Placement Test

\begin{tabular}{rrrrrr}
\hline & Grouping & N & Mean & Std. Deviation & Std. Error Mean \\
\hline Proficiency Test & Experimental & 25 & 43.8400 & 2.54427 & .50885 \\
& Control & 25 & 44.0000 & 2.04124 & .40825 \\
\cline { 2 - 6 }
\end{tabular}

To find out whether the two groups were homogeneous with regard to their English language proficiency, the scores of OPT were analyzed using an independent samples t-test was applied. Technically speaking, Table 3 indicates that $(\mathrm{t}$ $(48)=-.24, \alpha=.05, p=.8)$. It can be concluded that before the treatment the two groups were homogeneous with regard to their proficiency, so no significant difference was observed since the $p$ value (.8) is more than the alpha level (.05).

In order to check whether the participants enjoy an approximately the same level of writing ability, the pretest was administered. As can be seen in Table 4, there is no significant difference in the scores for the experimental group, teacher-led collaborative modelling $(\mathrm{M}=12.96, \mathrm{SD}=1.09)$ and the control group $(\mathrm{M}=11.72, \mathrm{SD}=.64)$. The comparison of the mean scores of the two groups indicates that the groups are very close in terms of their writing proficiency before the intervention.

Table 3. Independent Samples T-test for OQPT (Levene's Test for Equality of Variances)

\begin{tabular}{lrrrrrr}
\hline & F & Sig. & T & Df & Sig(2-ailed) & Mean Difference \\
\hline ProficiencyTest & 2.432 & .125 & -.245 & 48 & .807 & -.16000 \\
Equal variances & & & & & & \\
Assumed & & & & & & \\
\hline ProficiencyTest & 2.432 & .125 & -.245 & 45.845 & .807 & -.16000 \\
Equal variances & & & & & & \\
Not assumed & & & & & & \\
\hline
\end{tabular}

Table 4. Descriptive Statistics for the Writing Pretest

\begin{tabular}{rrrrrr}
\hline & Grouping & $\mathrm{N}$ & Mean & Std. Deviation & Std. Error Mean \\
\hline \multirow{2}{*}{ Writing Pretest } & Experimental & 25 & 12.4600 & 1.09848 & .21970 \\
& Control & 25 & 11.7200 & .64679 & .12936 \\
\hline
\end{tabular}

To find out whether any differences existed between the two groups, that is, teacher-led collaborative modeling group and the control group in the writing tasks, an independent samples t-test was applied. Table 5 indicates that the $\mathrm{p}$ value is more than $\alpha$, so there existed no difference between the two groups and they were homogeneous in terms of their writing ability. Put it technically, $(\mathrm{t}(48)=.94, \alpha=.05, p=.35, p>\alpha)$. Therefore, the groups had approximately the same level of writing proficiency (Mean Difference=.24).

Table 5.The Results of Independent Samples T-test for the Writing Test

\begin{tabular}{lrrrrrr}
\hline & \multicolumn{6}{c}{ Levene's Test for Equality of Variances } \\
\cline { 2 - 7 } & $\mathrm{F}$ & Sig. & $\mathrm{t}$ & $\mathrm{df}$ & Sig.(2-tailed) & Mean difference \\
\hline $\begin{array}{l}\text { WritingPre1 } \\
\text { Equal variances assumed }\end{array}$ & 1.502 & .226 & .941 & 48 & .351 & .24000 \\
\hline $\begin{array}{l}\text { WritingPre1 } \\
\begin{array}{l}\text { Equal Variances not } \\
\text { assumed }\end{array}\end{array}$ & 1.502 & .226 & .941 & 38.85 & .352 & .24000 \\
\hline
\end{tabular}

In order to find out whether the collaborative modeling had any effects on the writing performance of the participants, the posttest was administered. To do the analysis, an Independent samples t-test was utilized. Table 6, illustrating the descriptive statistics, demonstrates that the teacher-led collaborative modeling $(\mathrm{M}=17.70, \mathrm{SD}=1.48)$ significantly outperformed the control group $(\mathrm{M}=12.60, \mathrm{SD}=1.57)$.

Table 6. Descriptive Statistics for the Writing Posttest

\begin{tabular}{rrrrrr}
\hline & Treatment & N & Mean & Std. Deviation & Std. Error Mean \\
\hline \multirow{2}{*}{ Posttest } & Control & 25 & 12.60 & 1.570 & .346 \\
\cline { 2 - 6 } & Experimental & 25 & 17.70 & 1.484 & .267 \\
\hline
\end{tabular}


As indicated in Table 7, the results of an independent samples t-test reveal that there is a significant difference between the teacher-led collaborative modeling group and the control group. Technically speaking, $(\mathrm{t}(48)=-13.426, \alpha=.05, \alpha=$ $.05, p=.000)$. It shows that the $p$ value is less than the alpha level, so the intervention reached the significant level. It can be concluded that teaching writing through teacher-led collaborative modeling had a significant effect on the EFL upper-intermediate learners' writing performance. Therefore, the first null hypothesis is rejected corroborating that the writing ability through teacher-led collaborative modeling has been effective.

Table 7. The Results of Independent Samples T-test for the Writing Posttest

\begin{tabular}{|c|c|c|c|c|c|c|c|c|c|}
\hline & \multicolumn{2}{|c|}{$\begin{array}{l}\text { Levene's Test } \\
\text { for Equality of } \\
\text { Variances }\end{array}$} & \multicolumn{7}{|c|}{ t-test for Equality of Means } \\
\hline & $\mathrm{f}$ & Sig. & $\mathrm{T}$ & Df & $\begin{array}{l}\operatorname{Sig}(2- \\
\text { tailed })\end{array}$ & $\begin{array}{r}\text { Mean } \\
\text { difference }\end{array}$ & $\begin{array}{l}\text { Std. Error } \\
\text { Difference }\end{array}$ & $\begin{array}{l}95 \% \\
\text { Interval }\end{array}$ & $\begin{array}{l}\text { Confidence } \\
\text { of the } \\
\text { Difference }\end{array}$ \\
\hline & & & & & & & & lower & upper \\
\hline $\begin{array}{l}\text { Writing post1 } \\
\text { Equal Variances } \\
\text { Assumed }\end{array}$ & .807 & .325 & 13.426 & 48 & .000 & .5 .100 & .541 & -.7 .456 & 5.864 \\
\hline $\begin{array}{l}\text { Writing post1 } \\
\text { Equal Variances } \\
\text { Not Assumed }\end{array}$ & & & 13.426 & -5.263 & .000 & -6.100 & .541 & -7.457 & 5.764 \\
\hline
\end{tabular}

As shown in Table 8, there is a significant difference between the mean scores of the pre and posttests in the experimental group. In other words, the mean score for the experimental group in the posttest was larger than that of the pretest.

Table 8. Descriptive Statistics for the Experimental Group

\begin{tabular}{rrrrrr}
\hline & Mean & N & Std. Deviation & Std. Error Mean \\
\hline Pair 1 & Writing Pre1 & 12.46 & 25 & 1.09848 & .21970 \\
\hline & Writing Post1 & 17.70 & 25 & 1.16369 & 23274 \\
\hline
\end{tabular}

As shown in Table 9, the significance value for the difference between the pre and posttests in experimental group was found to be .000 which is significant at .05 level. In other words, $(\mathrm{t}(24)=-30.27, \alpha=.05, p=.000, p<\alpha)$. Therefore, it could be concluded that the experimental group made a significant difference in terms of their writing ability from the pretest to the posttest.

Table 9. The Results of Paired Samples T- test for The Experimental Group

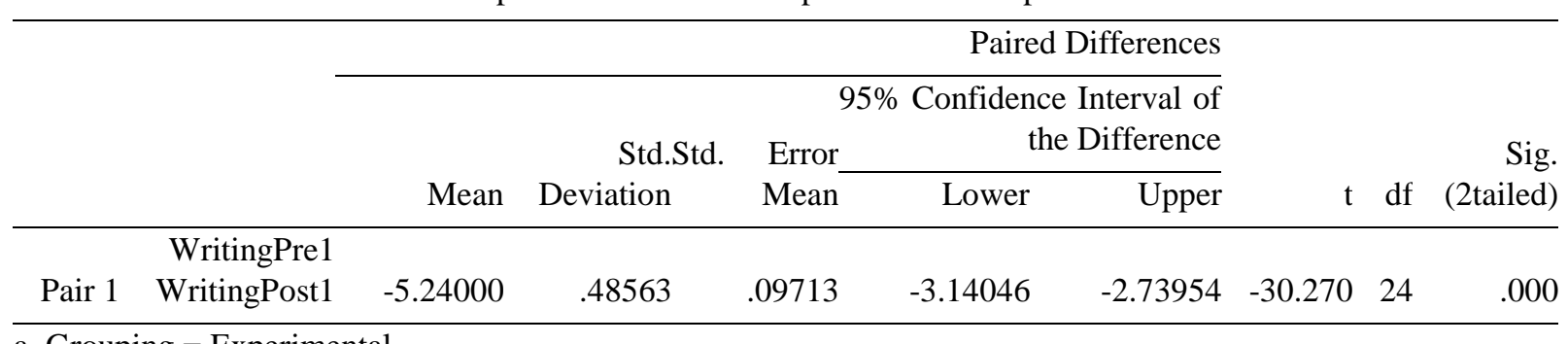

a. Grouping = Experimental

In order to find out whether teacher-led collaborative modeling would have any effect on EFL upper-intermediate learners' self-regulation, an independent samples t-test was utilized. Illustrates the descriptive statistics of the experimental and control groups. As can be seen in the same table, there is a difference in the mean scores for the experimental $(\mathrm{M}=94.04, \mathrm{SD}=10.78)$ and control groups $(\mathrm{M}=90.68, \mathrm{SD}=7.32)$. Based on their descriptive statistics, the two groups were approximately homogeneous in terms of their self-regulation. 
Table 10. Descriptive Statistics for the Pretest Self-regulation

\begin{tabular}{rrrrrr} 
& Grouping & $\mathrm{N}$ & Mean & Std. Deviation & Std. Error Mean \\
SRTotalPretest & Experimental & 25 & 94.0400 & 10.78765 & 2.15753 \\
\cline { 2 - 6 } & Control & 25 & 90.6800 & 7.32985 & 1.46597 \\
\hline
\end{tabular}

As indicated in Table 11, the results of an independent samples t-test reveal that there is no significant difference between the teacher-led collaborative modeling and self-regulation prior to the treatment. Technically speaking, ( $\mathrm{t}$ (48) $=1.28, \alpha=.05, p=.2, p>\alpha$ ). It shows that the $p$ value is more than the alpha level, so it has not reached the significant level. It can be concluded that the two groups are homogenous in terms of their self-regulation at the outset of the study.

In order to find out whether teacher-led collaborative modeling would have any effect on EFL upper-intermediate learners 'self-regulation, an independent samples t-test was utilized. Table 12 illustrates the descriptive statistics of the experimental and control groups. As can be seen in the same table, there is a difference in the mean scores for the experimental group $(M=103.28, S D=12.8)$ and the control group $(M=100.96, S D=6.8)$, but descriptive statistics do not spell out any significant difference, so t-test was run to see the possible differences.

Table 11.The Results of an Independent Samples T-test for the Pretest of Self-regulation

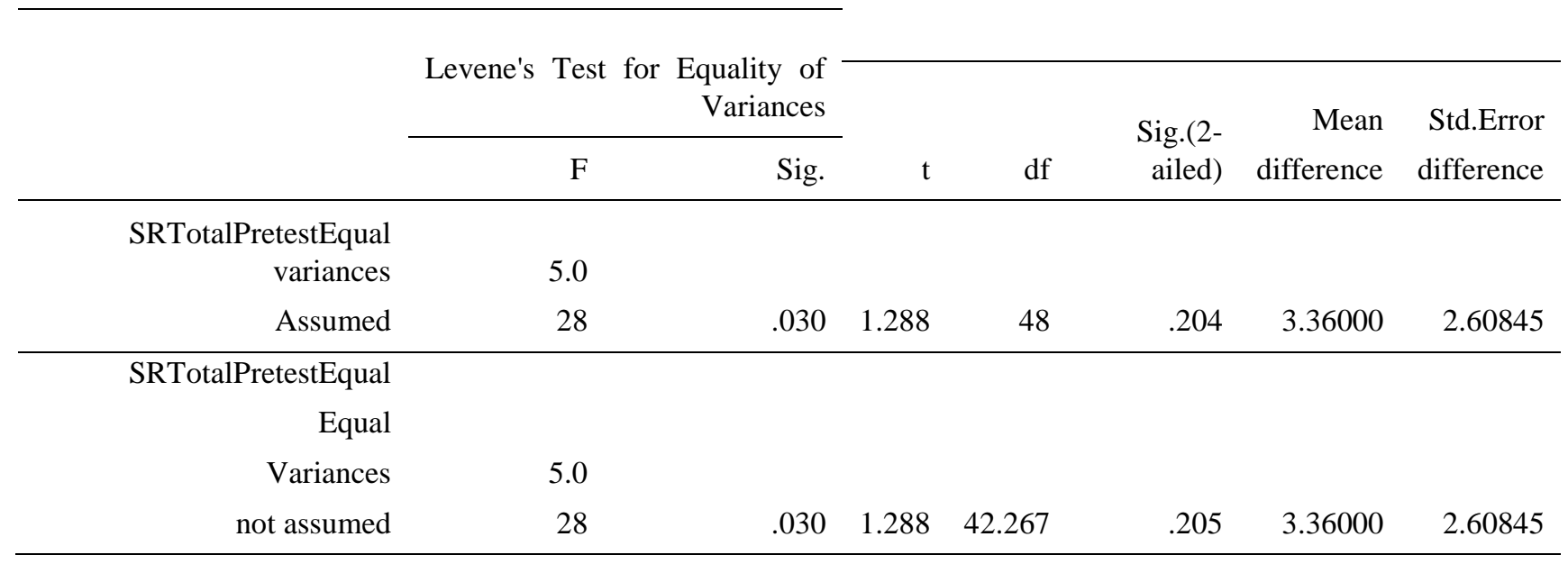

Table 12. Descriptive Statistics for the Pretest Self-regulation

\begin{tabular}{rrrrrr}
\hline & Grouping & N & Mean & Std. Deviation & Std. Error Mean \\
\hline SRTotalPosttest & Experimental & 25 & 103.2800 & 12.80143 & 2.56029 \\
\cline { 2 - 6 } & Control & 25 & 100.9600 & 6.80980 & 1.36196 \\
\hline
\end{tabular}

As indicated in Table 13, the results of an independent samples t-test reveal that there is no significant difference between the teacher-led collaborative modeling and self-regulation. Put it statistically, $(\mathrm{t}(48)=.8, \alpha=.05, p=.42, p>\alpha)$. It shows that the $p$ value is more than the alpha level, so the intervention has not reached the significant level. It can be concluded that teaching teacher-led collaborative modeling had no significant effect on the EFL upper-intermediate learners' self-regulation. Therefore, the second null hypothesis is not rejected corroborating that teacher-led collaborative has no effect on self-regulation.

Table 13. The Results of an Independent Samples T-test for the Posttest of Self-regulation

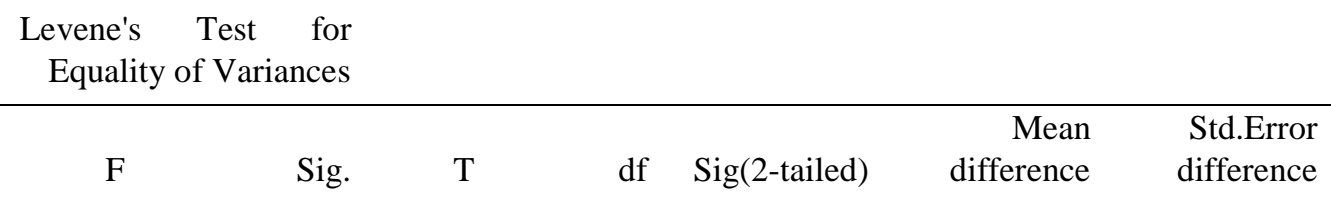

\section{SR Total Posttest}

Equal variances

\begin{tabular}{llllllllll} 
assumed & 6.96 & .011 & .800 & 48 & .428 & 2.32000 & 2.90000 \\
\hline
\end{tabular}

\section{SR Total Posttest}

Equal variances not assumed 6.96

.011

.800

36.576

.429

2.32000 


\section{Summary of findings}

In order to find out whether the collaborative modeling had any effects on the writing performance of the participants, the posttest was administered. To do the analysis, an Independent samples t-test was utilized. Table 6 demonstrates that the teacher-led collaborative modeling significantly outperformed the control group.

As indicated in Table 7, the results of an independent samples t-test reveal that there is a significant difference between the teacher-led collaborative modeling group and the control group. It can be concluded that teaching writing through teacher-led collaborative modeling had a significant effect on the EFL upper-intermediate learners' writing performance. Therefore, the first null hypothesis is rejected corroborating that the writing ability through teacher-led collaborative modeling has been effective.

As indicated in Table 11, the results of an independent samples t-test reveal that there is no significant difference between the teacher-led collaborative modeling and self-regulation prior to the treatment. It can be concluded that the two groups are homogenous in terms of their self-regulation at the outset of the study.

As indicated in Table 13, the results of an independent samples t-test reveal that there is no significant difference between the teacher-led collaborative modeling and self-regulation. It can be concluded that teaching teacher-led collaborative modeling had no significant effect on the EFL upper-intermediate learners' self-regulation. Therefore, the second null hypothesis is not rejected corroborating that teacher-led collaborative has no effect on self-regulation.

\section{Discussion}

The main purpose of this study was to explore the effects of teacher-led collaborative modeling on the EFL learners' writing performance and self-regulation. The results showed that teacher-led collaborative modeling had significant positive effects on the learners' learners' writing performance, but no significant effect on the learners' self-regulation. The findings also demonstrated a significant difference between the pre and posttests of the experimental group that can be interpreted as an improvement in writing performance due to the cooperation between teacher and learners in the teacher-led collaborative modeling.

This study benefited from the exploration that Wette (2015) had regarding the stages of collaborative modeling. In the pre-modelling stage the teacher tried to activate the learners' prior knowledge while triggering their interest through negotiation and discussion. Different choices for the writing activities were negotiated to come up with a wellconstructed piece of text. This teacher-led activity from the first step was accompanied by the interactions among students. Following this stage, the teacher tried to elicit feedback from students in the modeling stage while supporting and giving editing feedback. In post-modelling stage,_t the teacher tried to remove the immediate feedback and involve the learners in an independent construction of the texts. This type of modeling purposefully was found to be more supportive and less cognitive demanding for learners. This can increase the learners' interest, motivation and degree of participation in composing texts.

Considering this type of modeling as a scaffolded instruction where the teacher provides temporary support for completing a task (Van de Pol, Volman, \&Beishuizen, 2010). This type of support can help through using different types of modeling such as collaborative. One point that needs special attention is that the scaffolding provided here is a dynamic one and even in different phases of the collaborative modeling the teacher used it in different ways. This is because the interaction between the learners and teachers is fluid enough that needs different degrees and types of help.

\section{Conclusion}

Collaborative teaching can be considered as a new trend and among the latest attempts to provide educational services to EFL students. What was experienced in this study, especially in an EFL context is in line with the proponents of collaborative teaching. Teacher-led collaborative modeling in this study involved teachers and learners working as a community to negotiate and construct a process based piece of text. Besides raising the higher thinking process, the modeling episodes were representative of social learning in the L2 classroom writing. The conversations and interactions between the teachers and learners intensified the cognitive demand of the writing tasks done through the episodes of the modeling. This type of activity provided scaffolding instruction through which tasks were achieved and the adapted help of the teacher led to the developmental needs of the learners. While the teacher provided purposeful help in this model, he was conscious to withdraw his support as the competence of the learners and they were little by little able to do the task independently. This was done on the premise that the learners' self-regulated strategies in writing would be developed as they attempted the skills and strategies needed in composing, revising and evaluating the writing tasks.

It is notable that in Collaborative teacher-led approach, the cognitive demand of the writing tasks can be shifted from learners to teachers in a way that the teachers would need mental effort, concentration and recognition of the learners' ability and learning needs in the class. This, in fact, makes the job more challenging for the teachers to decide the amount of help needed for learners to have an appropriate contribution in the tasks.

\section{Pedagogical Implications}

The results of this study may have various kinds of pedagogical implications for Teaching English as a Foreign Language (TEFL), EFL learners as well as teachers and also syllabus designers who have a contribution to the field.

Collaborative teacher-led modeling will provide language teachers with precious feedback related to the learners' needs for demanding skills in an academic writing course. This approach will also help teachers distinguish the learners' level, 
degree of contribution they may have as well as the amount of support they need in this regard. EFL teachers can also rely on the social community provided in the class and take advantage of this condition to involve students in a cooperative, constructive context, particularly for an L2 writing classroom where the learners can collaboratively enjoying their teacher's support compose writing tasks.

This type of modeling provides an opportunity for EFL teachers to share the mental, cognitive effort the writing tasks need to compose and take steps towards facilitating and supporting the learning process in a social cooperative milieu. This approach can be followed by a gradual withdraw of support so that learners move to a stepwise autonomy in doing their writing tasks.

Teacher-led collaborative modeling in L2 writing can construct a gradual interest and motivation in participation of the EFL learners as it enjoys a support from the teacher in a social cooperative condition. The learners in this context will have the opportunity to help and support their peers under the guidance of the teacher and advance their learning by getting insights from the thinking process of other capable students as well as their teacher. Besides the pedagogical implications that each phase of the modeling has for learners the post-modeling phase can help learners attempt the academic tasks in other subject areas as well.

\section{Implications and Suggestions for Further Research}

This study can be done in a wider scope not only in the field of EFL but in other academic disciplines where academic writing has a pivotal role in their participants' accomplishments. Teacher-led collaborative modeling in L2 writing can pave the way to the benefits of scaffolded instructions. Taking advantage of this type of instructions, practitioners can investigate the possible sociocultural effects of this modeling such as the learners' attitudes, motivation as well as social interactions.

There can also be other studies considering the effect of this approach on the degree of learners' contribution to the activities independently. The amount of time allocated for each phase of this modeling can be regarded as a subject of another study.

\section{References}

Bauwens, J., Hourcade, J. J., \& Friend, M. (1989). Cooperative Teaching A Model for General and Special Education Integration. Remedial and Special Education, 10(2), 17-22.

Bitchener, J. (2012). A reflection on 'the language learning potential'of written CF. Journal of Second Language Writing, 21(4), 348-363.

Bochenek, Heather L. Approving or disapproving: Parent perceptions of inclusion at the elementary level. ProQuest, 2008.

Chukharev-Hudilainen, E., \&Saricaoglu, A. (2014). Causal discourse analyzer: improving automated feedback on academic ESL writing. Computer Assisted Language Learning, 1-23.

Dörnyei, Z., \&Ushioda, E. (2013). Teaching and researching: Motivation. Routledge.

Ferris, D., \&Hedgcock, J. S. (2005). Teacher response to student writing: Issues in oral and written feedback. Teaching ESL composition: Purpose, process and practice, 184-222.

Hinkel, E. (Ed.). (2011). Handbook of research in second language teaching and learning (Vol. 2). Routledge.

Hyland, K. (2013). Writing in the university: education, knowledge and reputation. Language teaching, 46(01), 53-70.

Kanno, Y., \& Varghese, M. M. (2010). Immigrant and refugee ESL students' challenges to accessing four-year college education: From language policy to educational policy. Journal of Language, Identity, and Education, 9(5), 310-328.

Kauffman, D. F. (2004). Self-regulated learning in web-based environments: Instructional tools designed to facilitate cognitive strategy use, metacognitive processing, and motivational beliefs. Journal of educational computing research, 30(1-2), 139-161.

Kibler, A. K., Heny, N. A., \& Andrei, E. (2015).In-Service Teachers' Perspectives on Adolescent ELL Writing Instruction. TESOL Journal.

Louth, R., McAllister, C., \& McAllister, H. A. (1993).The effects of collaborative writing techniques on freshman writing and attitudes. The Journal of experimental education, 61(3), 215-224.

Macbeth, K. P. (2010). Deliberate false provisions: The use and usefulness of models in learning academic writing. Journal of Second Language Writing, 19(1), 33-48.

Myles, J. (2002). Second language writing and research: The writing process and error analysis in student texts. Tesl$E j, 6(2), 1-20$.

Nishino, T., \& Atkinson, D. (2015).Second language writing as sociocognitive alignment. Journal of Second Language Writing, 27, 37-54.

Nishino, T., \& Atkinson, D. (2015).Second language writing as sociocognitive alignment. Journal of Second Language Writing, 27, 37-54. 
Scardamalia, M., \&Bereiter, C. (1987).Knowledge telling and knowledge transforming in written composition. Advances in applied psycholinguistics, 2, 142-175.

Silvia, P. J. (2008). Interest - the curious emotion. Current Directions in Psychological Science, 17(1), 57-60.

Stetsenko, A., \&Arievitch, I. (1997). Constructing and deconstructing the self: Comparing post-Vygotskian and discourse-based versions of social constructivism. Mind, Culture, and Activity, 4(3), 159-172.

Stone, P. (1998). Layered learning in multiagent systems: A winning approach to robotic soccer. MIT Press.

Storch, N. (2002). Patterns of interaction in ESL pair work. Language learning, 52(1), 119-158.

Storch, N. (2005). Collaborative writing: Product, process, and students' reflections. Journal of second language writing, 14(3), 153-173.

Topping, K. (1998). Peer assessment between students in colleges and universities. Review of educational Research, 68(3), 249-276.

Topping, K. J., \&Ehly, S. W. (2001). Peer assisted learning: A framework for consultation. Journal of Educational and Psychological Consultation, 12(2), 113-132.

Van de Pol, J., Volman, M., \&Beishuizen, J. (2010). Scaffolding in teacher-student interaction: A decade of research. Educational Psychology Review, 22(3), 271-296.

Wette, R. (2015). Teacher-led collaborative modelling in academic L2 writing courses. ELT Journal, 69(1), 71-80.

Yarrow, F., \& Topping, K. J. (2001). Collaborative writing: The effects of metacognitive prompting and structured peer interaction. British journal of educational psychology, 71(2), 261-282. 